\title{
Influência dos elementos meteorológicos na produção de adubos verdes, em diferentes épocas de semeadura ${ }^{1}$
}

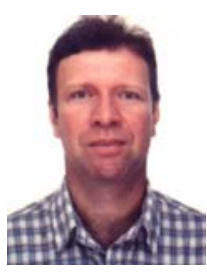

Vanderley S. dos Santos² \& José H. Campelo Júnior ${ }^{3}$

\begin{abstract}
1 Parte da Dissertação de Mestrado apresentada pelo primeiro autor à UFMT
2 Escola Agrotécnica Federal de Cuiabá. Rodovia $\mathrm{Br} 364, \mathrm{~km}$ 329, São Vicente da Serra, CEP-78106-000, Cuiabá, MT. Fone: (65) 621-4338. E-mail: rovan@terra.com.br (Foto)

${ }^{3}$ Departamento de Solos da Faculdade de Agronomia e Medicina Veterinária da UFMT. Av. Fernando Correia da Costa s/n, CEP: 78060-900.E-mail: jcampelo@terra.com.br
\end{abstract}

Protocolo 69 - 10/5/2002 - Aprovado em 21/2/2003

\begin{abstract}
Resumo: Para se estudar a influência do saldo de radiação solar, temperatura do ar, precipitação e fotoperíodo no rendimento em fitomassa e na data de florescimento da Crotalaria juncea e da Mucuna aterrima, foi conduzido um experimento em São Vicente da Serra, MT, na área experimental da Escola Agrotécnica Federal de Cuiabá, em 1999 e 2000. O delineamento experimental usado foi o de blocos ao acaso, com três repetições. A mucuna apresentou maiores rendimentos em fitomassa; a relação $E T_{r} / E T_{p}$ foi a variável que melhor se correlacionou com o rendimento da mucuna e, com a crotalária, foi o fotoperíodo. O florescimento da mucuna foi afetado pela temperatura e o da crotalária, pelo fotoperíodo.
\end{abstract}

Palavras-chave: Crotalaria juncea, Mucuna aterrima, datas de plantio

\section{Influence of the meteorological elements in the production of green manures sown in different periods}

\begin{abstract}
With the objective to study the influence of the net radiation, air temperature, precipitation and photoperiod in the phytomass production and flowering date of Crotalaria juncea and Mucuna aterrima, an experiment was conducted in São Vicente da Serra, MT, in the experimental area of Escola Agrotécnica Federal de Cuiabá, MT, Brazil, during 1999 and 2000. The experimental design was the randomized blocks, with three replications. The Mucuna yield was higher at all times; the relation $\mathrm{ET}_{\mathrm{r}} / \mathrm{ET}_{\mathrm{p}}$ was the variable that best correlated with Mucuna yield, while in the Crotalaria it was photoperiod. Flowering of Mucuna was affected by the temperature, where as for the Crotalaria it was affected by photoperiod.
\end{abstract}

Key words: Crotalaria juncea, Mucuna aterrima, sowing date

\section{INTRODUÇÃO}

Em geral, os rendimentos agrícolas dos cerrados superam a média brasileira, mas são ainda considerados baixos, quando comparados ao seu potencial de rendimento ou aos rendimentos obtidos em áreas que empregam tecnologias mais avançadas (Caruso, 1997 e Urchei et al., 2000).

As principais causas desses baixos rendimentos podem ser atribuídas aos solos dos cerrados que, em geral, apresentam baixa fertilidade natural, saturação em ferro e alumínio e baixa capacidade de retenção de água. Além disso, o uso de técnicas de manejo que degradam os solos e o regime pluviométrico que limita os cultivos ao período entre setembro a abril também contribuem para que os rendimentos agrícolas nessa região sejam baixos.
Apesar dessas deficiências, os cerrados apresentam fatores favoráveis ao aumento da produção de alimentos, fibras e energia (Fageria \& Souza, 1995). Com a utilização de tecnologias e estratégias de manejo adequadas é possível melhorar os rendimentos e minimizar a degradação dos solos.

Uma das alternativas para o desenvolvimento agrícola sustentável do cerrado pode ser o uso da adubação verde. Conforme Souza (1989) esta modalidade de adubação orgânica mobiliza nutrientes, combate nematóides e plantas invasoras, reduz gastos com fertilizantes minerais, principalmente nitrogenados, protege o solo diminuindo a erosão causada pelas chuvas e pode promover aumentos nos rendimentos com as principais culturas. Segundo Malavolta et al. (2000) os adubos verdes são importantes na melhoria das propriedades físicas, químicas e biológicas dos solos. 
Entre as espécies mais usadas como adubos verdes estão a Mucuna aterrima (Piper \& Tracy) Merr. e a Crotalaria juncea L., conhecidas por mucuna preta e crotalária juncea. A mucuna se destaca pelo desenvolvimento sob déficit hídrico e altas temperaturas e a crotalária pela produção de fitomassa (Amabile, 1996).

Uma espécie vegetal só expressará seu potencial produtivo se manejada na época adequada e de forma correta. Para melhorar o rendimento de um vegetal é fundamental que ocorra interação entre genótipo e ambiente. Sendo assim, é importante a sincronização entre os estádios vegetativo e reprodutivo das plantas com as alterações meteorológicas (Peixoto, 1998).

Considerando-se esses aspectos, podem ocorrer épocas de semeaduras mais adequadas, quando a crotalária e a mucuna atingirem ou se aproximarem do seu rendimento máximo. Como os elementos meteorológicos atuam diferentemente em cada época e local, a precipitação, a radiação solar, a temperatura do ar e o fotoperíodo, podem influenciar significativamente a produção de fitomassa desses adubos verdes.

O objetivo deste trabalho foi avaliar os efeitos da radiação solar, temperatura, precipitações e fotoperíodo no rendimento em fitomassa e no florescimento da Crotalaria juncea L. e da Mucuna aterrima (Piper \& Tracy) Merr., cultivadas em diferentes épocas do ano e em área edafo-climaticamente representativa do Cerrado.

\section{MATERIAL E MÉTODOS}

O experimento foi conduzido em São Vicente da Serra, MT, na área experimental da Escola Agrotécnica Federal de Cuiabá, situada a $15^{\circ} 45^{\prime}$ de latitude Sul e $55^{\circ} 25^{\prime}$ de longitude Oeste e $780 \mathrm{~m}$ de altitude, no período de novembro de 1999 até outubro de 2000. Conforme Nimer (1989) o local apresenta temperatura média anual de $22^{\circ} \mathrm{C}$ e precipitação de $1.500 \mathrm{~mm}$ a $1.750 \mathrm{~mm}$ (Brasil, 1982) que, conforme os critérios de Köppen, caracteriza o clima como Aw (tropical chuvoso de savana).

O Laboratório do Centro Nacional de Pesquisa de Solo (EMBRAPA-CNPS) identificou o solo do local como Latossolo Vermelho-Escuro distrófico, A moderado, textura argilosa, savana arbórea/florestas de galeria, suave ondulado/ondulado (Oliveira, 2000).

O solo foi preparado de forma convencional, constando de aração com arado de disco de 28 ", seguido de gradagem niveladora. $\mathrm{O} \mathrm{pH}$ foi corrigido com aplicação de $2 \mathrm{t} \mathrm{ha}^{-1}$ de calcário. Aplicou-se também o herbicida preemergente trifluralina, na dose de $1,2 \mathrm{~L} \mathrm{ha}^{-1}$ e calda de $500 \mathrm{~L} \mathrm{ha}^{-1}$. Previamente à realização das semeaduras foram efetuadas uma capina, uma limpeza e a abertura dos sulcos de semeadura de $0,05 \mathrm{~m}$ com enxadas e rastelos.

As espécies estudadas, Crotalaria juncea L. e a Mucuna aterrima (Piper \& Tracy) Merr., foram semeadas manualmente em espaçamentos de 0,5 m em: 5/11/99 (nov.); 4/12/1999 (dez.); 5/1/2000 (jan.); 4/2/2000 (fev.); 5/3/2000 (mar.); 4/4/2000 (abr.); 5/5/2000 (maio); 5/6/2000 (jun.). A população de plantas por metro linear para a mucuna foi de aproximadamente $20 \mathrm{e}$, para a crotalária, de 25.
O delineamento experimental foi de blocos ao acaso, com três repetições. As parcelas experimentais tinham 6,0 x 6,0 m, constituídas por 13 linhas de semeadura. Para a coleta das amostras foram utilizadas apenas 4 linhas descontando-se, como bordadura, $0,5 \mathrm{~m}$ nas extremidades e 3 linhas nas laterais.

As avaliações da produção de fitomassa seca foram realizadas quando as plantas completaram o subperíodo emergência-florescimento. O número de dias para o florescimento foi determinado contando-se os dias desde a emergência até que $50 \%$ das plantas da linha central da parcela apresentassem tanto flores como botões florais.

Após a coleta das plantas, as amostras foram embaladas em sacolas de papel e colocadas em estufa de ventilação forçada de ar, em temperatura de $65^{\circ} \mathrm{C}$ por $72 \mathrm{~h}$. Após a secagem, foram pesadas em balança analítica e a produção de fitomassa seca foi expressa em $\mathrm{kg} \mathrm{m}^{-2}$.

A temperatura média do ar, a precipitação convencional e a insolação, foram obtidas junto à estação meteorológica do Instituto Nacional de Meteorologia (INMET) localizada a $800 \mathrm{~m}$ do experimento.

A radiação solar global e o saldo de radiação foram calculados conforme Tubelis \& Nascimento (1992). Considerando-se que as condições ambientais variáveis ao longo do ano poderiam afetar a umidade e o grau de cobertura do solo proporcionado pelas duas leguminosas avaliadas, o albedo, ou poder refletor da superfície (r) assumido, correspondeu ao valor médio entre o da cultura do feijão $(0,24)$ e o do solo arado úmido $(0,15)$. A radiação fotossinteticamente ativa (PAR) foi estimada usando-se a metodologia de Barni et al. (1995a) que a consideram como $46 \%$ da radiação solar global.

O fotoperíodo foi calculado conforme metodologia apresentada por Camargo (1985). A temperatura mínima basal (Tb) foi determinada conforme Ometto (1981). O cálculo das unidades térmicas de crescimento ou Graus-Dia (GD) necessários para o ciclo emergência - floração foi realizado conforme a equação apresentada em Camargo et al. (1987).

Para o cálculo do balanço hídrico seqüencial diário, utilizouse uma planilha eletrônica elaborada por Rolim et al. (1998). No cálculo da capacidade de água disponível do solo, usaram-se os parâmetros físicos publicados em Oliveira (2000) que apresenta umidade na capacidade de campo de $30,84 \%$, ponto de murcha permanente de $15,98 \%$ e densidade aparente de $1,28 \mathrm{~kg} \mathrm{dm}^{-3}$. A profundidade do sistema radicular adotada foi $90 \mathrm{~cm}$. Esses dados foram aplicados na seguinte equação:

$$
\mathrm{CAD}=0,1(\mathrm{CC} \%-\mathrm{PM} \%) \mathrm{ds} \mathrm{z}
$$

em que:

$\mathrm{CAD}$ - capacidade de água disponível $(\mathrm{mm})$

CC - capacidade de campo expresso em \% (peso)

PM - ponto de murcha permanente expresso em \% (peso)

z - profundidade efetiva do sistema radicular das culturas (cm)

ds - densidade do solo $\left(\mathrm{kg} \mathrm{dm}^{-3}\right)$

Foram aplicados os testes de Lilliefors e Bartlett (SAEG 5.0) para verificar a normalidade e a homogeneidade das variâncias, 
respectivamente, procedendo-se transformação em raiz quadrada de $(\mathrm{x}+1)$ para a realização da análise de variância. $\mathrm{O}$ teste de significância de $\mathrm{F}$ foi ao nível de $5 \%$ de probabilidade.

\section{RESULTADOS E DISCUSSÃO}

Através da análise de variância para a variável fitomassa seca, observou-se efeito significativo das épocas de semeadura das espécies de adubo verde e da interação entre épocas e espécies.

O efeito significativo das épocas de semeadura sobre a produção de fitomassa seca pode ser atribuído às variações de temperatura do ar, disponibilidade de radiação solar, água no solo e luz. Como se trata de adubos verdes de verão (Calegari 1995), tal efeito era esperado, uma vez que as semeaduras foram realizadas também no outono e no inverno, períodos em que ocorre redução de temperatura do ar, da precipitação e de insolação. As diferenças de rendimento podem ser atribuídas à capacidade peculiar de cada espécie em suportar as variações meteorológicas durante a condução do experimento e estão apresentadas na Tabela 1 e na Figura 1.

Tabela 1. Valores médios* de radiação solar, temperatura do ar, fotoperíodo e precipitação acumulada, da semeadura ao florescimento com a mucuna preta e a crotalária em oito épocas de semeadura (ES), em São Vicente da Serra, MT

\begin{tabular}{lccccc} 
Espécies & $\mathrm{ES}^{* *}$ & $\begin{array}{c}\text { Radiação } \\
\left(\mathrm{MJ} \mathrm{m}^{-2} \mathrm{~d}^{-1}\right)\end{array}$ & $\begin{array}{c}\text { Temp. } \\
\left({ }^{\circ} \mathrm{C}\right)\end{array}$ & $\begin{array}{c}\text { Fotoperíodo } \\
(\mathrm{h})\end{array}$ & $\begin{array}{c}\text { Precipitação } \\
(\mathrm{mm})\end{array}$ \\
\hline Mucuna & 1 & 12,36 & 23,4 & 14,04 & 801,0 \\
Crotalária & 1 & 13,34 & 23,3 & 14,15 & 509,7 \\
Mucuna & 2 & 11,24 & 23,2 & 13,89 & 784,1 \\
Crotalária & 2 & 11,59 & 23,1 & 14,09 & 499,8 \\
Mucuna & 3 & 11,07 & 23,1 & 13,54 & 774,6 \\
Crotalária & 3 & 11,22 & 23,1 & 13,92 & 425,4 \\
Mucuna & 4 & 10,51 & 22,8 & 13,21 & 621,6 \\
Crotalária & 4 & 10,13 & 22,9 & 13,55 & 440,6 \\
Mucuna & 5 & 10,66 & 22,5 & 12,82 & 352,0 \\
Crotalária & 5 & 10,91 & 23,0 & 13,16 & 312,5 \\
Mucuna & 6 & 9,77 & 21,6 & 12,54 & 159,8 \\
Crotalária & 6 & 10,85 & 22,8 & 12,99 & 155,1 \\
Mucuna & 7 & 9,81 & 21,8 & 12,74 & 182,2 \\
Crotalária & 7 & 10,37 & 22,0 & 12,47 & 0,0 \\
Mucuna & 8 & 10,20 & 22,4 & 12,97 & 175,8 \\
Crotalária & 8 & 8,55 & 19,0 & 12,42 & 6,3 \\
\hline
\end{tabular}

* Dados até o trigésimo dia após a semeadura

** 1.5/11/1999; $2.4 / 12 / 1999 ; 3.5 / 1 / 2000 ; 4.4 / 2 / 2000 ; 5.5 / 3 / 2000 ; 6.4 / 4 / 2000 ; 7.5 / 5 / 2000 ; 8.5 / 6 / 2000$ Fonte: Estação Climatológica de São Vicente da Serra, MT, $9^{\circ}$ Distrito de Meteorologia - Instituto Nacional de Meteorologia (INMET)

Portanto, houve diferença significativa entre os valores de produção de fitomassa em pelo menos uma das épocas, para as duas espécies.

Em todas as épocas, a mucuna apresentou maiores rendimentos que a crotalária mas, nas quarta, sétima e oitava épocas de semeadura, as duas espécies não apresentaram diferenças significativas de rendimento, como se pode observar na Tabela 2. Na média das oito épocas, a mucuna também apresentou maior rendimento em fitomassa que a crotalária. Resultados semelhantes foram obtidos por Espíndola et al. (1998) que atribuíram esta diferença de rendimento à sensibilidade fotoperiódica apresentada pela crotalária; entretanto, o

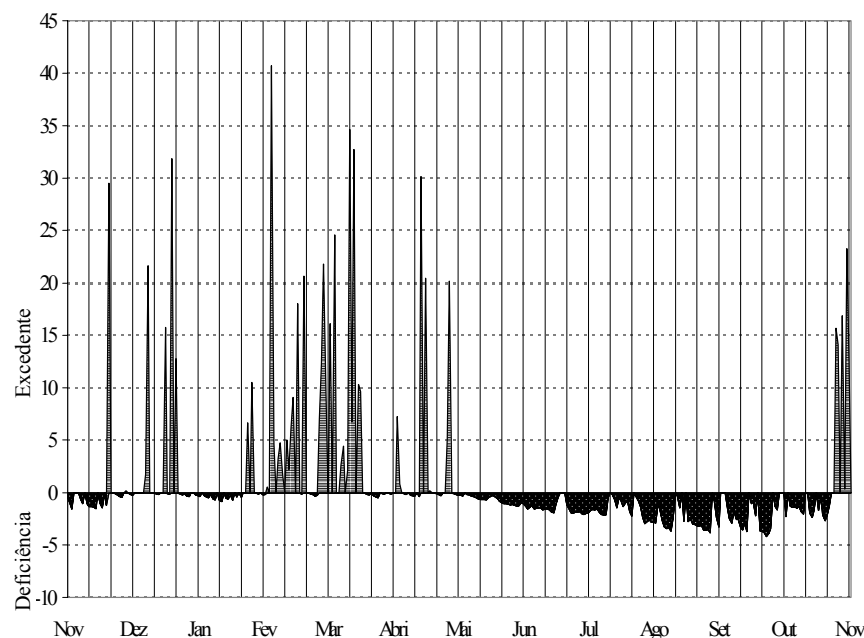

Figura 1. Extrato do balanço hídrico seqüencial diário segundo método de Thornthwaite \& Mather (1955), para São Vicente da Serra, MT, correspondente ao período de outubro/99 a novembro/00

resultado do presente trabalho não coincide com estudos realizados na Fazenda Experimental da Universidade Federal de Mato Grosso (UFMT) onde, conforme Pacheco \& Campelo Jr. (2001), a crotalária tem superado outras leguminosas avaliadas na região.

Tabela 2. Médias* de produção de fitomassa dos adubos verdes mucuna preta e crotalária juncea em oito épocas de semeadura, em São Vicente da Serra, MT, entre novembro de 1999 e outubro de 2000

\begin{tabular}{lll}
\hline Época de & Mucuna & Crotalária \\
\cline { 2 - 3 } Semeadura & \multicolumn{2}{c}{$\mathrm{kg} \mathrm{m}^{-2}$} \\
\hline (1) $5 / 11 / 99$ & $1,570 \mathrm{a} \mathrm{A}$ & $0,882 \mathrm{~b} \mathrm{~A}$ \\
(2) $4 / 12 / 99$ & $1,270 \mathrm{a} \mathrm{A}$ & $0,864 \mathrm{~b} \mathrm{~A}$ \\
(3) $5 / 1 / 00$ & $1,283 \mathrm{a} \mathrm{A}$ & $0,276 \mathrm{~b} \mathrm{~B}$ \\
(4) $4 / 2 / 00$ & $0,423 \mathrm{a} \mathrm{B}$ & $0,295 \mathrm{a} \mathrm{B}$ \\
(5) $5 / 3 / 00$ & $0,492 \mathrm{a} \mathrm{B}$ & $0,060 \mathrm{~b} \mathrm{C}$ \\
(6) $5 / 4 / 00$ & $0,477 \mathrm{a} \mathrm{B}$ & $0,096 \mathrm{~b} \mathrm{~B} \mathrm{C}$ \\
(7) $5 / 5 / 00$ & $0,327 \mathrm{a} \mathrm{B}$ & $0,044 \mathrm{a} \mathrm{C}$ \\
(8) $5 / 6 / 00$ & $0,068 \mathrm{a} \mathrm{C}$ & $0,000 \mathrm{a} \mathrm{C}$ \\
\hline Média & $0,738 \mathrm{a}$ & $0,314 \mathrm{~b}$ \\
\hline
\end{tabular}

" Médias das linhas seguidos das mesmas letras minúsculas e das colunas por letras maiúsculas não diferem entre si pelo teste de Tukey, ao nível de $5 \%$ de probabilidade. As médias apresentadas correspondem aos valores reais observados; entretanto, o teste de médias foi efetuado com os valores transformados

O desdobramento de época para cada espécie mostrou que a época de semeadura interferiu no rendimento das duas espécies. A mucuna preta, embora tenha apresentado maior produção, foi mais afetada com a variação das épocas de semeadura em seu rendimento que a crotalária. Os rendimentos mais expressivos com a mucuna foram nas primeira, segunda e terceira épocas mas, nas semeaduras tardias, ocorreram reduções significativas na produção de fitomassa (Tabela 2). Estudos de Fornasieri Filho et al. (1989) confirmam a influência das épocas de semeadura sobre o comportamento da mucuna, que diminuiu o rendimento com o atraso da semeadura.

Os maiores rendimentos com a mucuna foram obtidos nas três primeiras épocas e não apresentaram diferenças significa- 
tivas entre eles (Tabela 2). Em seguida, as semeaduras de março, abril, fevereiro e maio, também não apresentaram diferenças significativas. Assim como Calegari et al. (1995) esses resultados levam a recomendar a mucuna para semeaduras em novembro, dezembro e janeiro, quando o objetivo for maior produção de fitomassa e o cultivo for exclusivo.

$\mathrm{Na}$ semeadura de fevereiro, a mucuna foi severamente atacada por insetos; por isto, apresentou rendimento de apenas $0,423 \mathrm{~kg} \mathrm{~m}^{-2}$. Nessa época, as variáveis meteorológicas apresentavam-se com valores semelhantes aos ocorridos nas três primeiras épocas, favoráveis, portanto, à obtenção de rendimentos semelhantes aos obtidos nas três primeiras épocas.

Analisando-se a Tabela 2, percebe-se um desempenho bastante inferior da mucuna na oitava época de semeadura em relação às demais épocas, quando ocorreu o pior rendimento $\left(0,068 \mathrm{~kg} \mathrm{~m}^{-2}\right)$. O extrato do balanço hídrico (Figura 1) indica que, nessa época, ocorreram períodos em que as plantas foram submetidas à severa deficiência hídrica.

Conforme se observa na Tabela 1 e na Figura 1, a partir da quarta época a mucuna foi submetida a alterações significativas nos valores médios dos elementos meteorológicos, principalmente das precipitações e temperaturas, que se reduziram em relação às épocas anteriores. A sétima e a oitava semeaduras, foram as de maior deficiência hídrica, que ocorreu diariamente, desde a semeadura. Essas reduções no volume de chuvas e na temperatura média impediram a emergência de plantas. Segundo Bulisani \& Roston (1993) a insuficiência hídrica e a térmica prejudicam o estabelecimento das diferentes culturas.

$\mathrm{Na}$ sétima e na oitava épocas de semeadura, a mucuna respondeu às influências meteorológicas, apresentando pouca evolução no crescimento e, conseqüentemente, na produção de matéria seca, durante os meses de maio, junho e julho e meados de agosto, voltando a apresentar crescimento após as chuvas de maior intensidade, que ocorreram a partir da segunda quinzena de agosto e, também, após o aumento nos valores médios apresentados pelos demais elementos meteorológicos, conforme a Tabela 3 e a Figura 1. Este comportamento foi semelhante ao verificado por Pinto et al. (2001) que descrevem o fenômeno como uma estratégia de sobrevivência das plantas frente à diminuição da disponibilidade de água no solo. Arf et al. (1999) atribuem, às temperaturas baixas e, principalmente, à menor ocorrência de chuvas nos meses de abril, maio e junho,

Tabela 3. Médias dos elementos meteorológicos acumulados de novembro de 1999 até outubro de 2000

\begin{tabular}{lcccc} 
Mês & $\begin{array}{c}\text { Precipitação } \\
(\mathrm{mm})\end{array}$ & $\begin{array}{c}\text { Fotoperíodo } \\
(\mathrm{h})\end{array}$ & $\begin{array}{c}\text { Radiação } \\
\left(\mathrm{MJ} \mathrm{m}^{-2} \mathrm{dia}^{-1}\right)\end{array}$ & $\begin{array}{c}\text { Temperatura } \\
\left({ }^{\circ} \mathrm{C}\right)\end{array}$ \\
\hline Nov. & 165,4 & 14,08 & 15,57 & 22,8 \\
Dez. & 202,8 & 14,23 & 11,96 & 23,4 \\
Jan. & 146,3 & 14,14 & 12,82 & 23,5 \\
Fev. & 229,1 & 13,82 & 10,84 & 22,8 \\
Mar. & 283,4 & 13,38 & 9,64 & 22,9 \\
Abril & 190,5 & 12,93 & 11,31 & 22,9 \\
Maio & 6,8 & 12,55 & 10,06 & 21,7 \\
Jun. & 6,4 & 12,38 & 9,20 & 21,5 \\
Julho & 4,3 & 12,46 & 8,86 & 19,0 \\
Ago. & 36,7 & 12,78 & 9,75 & 23,5 \\
Set. & 84,2 & 13,22 & 10,67 & 22,6 \\
Out. & 202,4 & 13,64 & 12,79 & 24,7 \\
\hline Fin
\end{tabular}

Fonte: INMET as reduções no rendimento de matéria seca com a mucuna preta, salientando que esta espécie foi afetada em seu desenvolvimento, por esses elementos.

Como se pode verificar, pelo valor significativo de $\mathrm{F}$ para o desdobramento de época dentro de cada espécie, o adubo verde Crotalaria juncea $\mathrm{L}$., assim como a mucuna preta, também foi afetado pela época de semeadura. A crotalária apresentou produção de fitomassa em quantidade satisfatória apenas na primeira e na segunda épocas $\left(0,882\right.$ e $\left.0,864 \mathrm{~kg} \mathrm{~m}^{-2}\right)$. A partir da terceira época houve redução acentuada nos rendimentos (Tabela 2).

Os rendimentos da crotalária nas épocas três, quatro e seis, não foram significativamente diferentes entre si (Tabela 2). No entanto, observa-se que na terceira e na quarta épocas de semeadura, os rendimentos foram quase três vezes menores que os rendimentos obtidos nas duas primeiras épocas e bastante superiores ao rendimento obtido em demais época de semeadura. Os piores rendimentos com a crotalária ocorreram nas sexta (abril), quinta (mar), sétima (maio) e oitava (jun) épocas de semeadura.

Os rendimentos da terceira até a oitava época, podem comprometer o emprego da crotalária para semeaduras nessas épocas, uma vez que rendimentos abaixo de $0,400 \mathrm{~kg} \mathrm{~m}^{-2}$ não apresentam efeitos significativos no aumento de $\mathrm{N}$ ao solo (Abboud, 1986).

As diferenças de produção de fitomassa verificadas com a crotalária podem ser atribuídas às variações no ambiente, ocorridas com o atraso das semeaduras, principalmente com as variações do fotoperíodo. Sobre esta possibilidade, nota-se que, a partir de janeiro (Tabela 3) o comprimento dos dias foi diminuindo, acarretando menor número de dias necessários para o florescimento e redução na altura média das plantas, com conseqüente queda na produção de fitomassa seca com a crotalária. Resultados semelhantes foram observados por Alcântara et al. (2000) que atribuíram essa redução nos rendimentos à sensibilidade dessa espécie ao fotoperíodo. Estudos de Fornasieri Filho et al. (1989) e Amabile (1996) apresentaram o mesmo efeito, confirmando a interferência da época de semeadura sobre a matéria seca acumulada por esse adubo verde.

O rendimento de fitomassa seca com a crotalária foi reduzido com o atraso nas semeaduras, descartando-se a possibilidade de recomendar esta espécie em semeaduras, que visem alta produção de fitomassa, em épocas mais tardias. Da mesma forma, Calegari (1995) recomenda a semeadura da Crotalária juncea no sul do Brasil, para o período de setembro a dezembro, aludindo-se ao fato de que plantios realizados em janeiro e fevereiro encurtam o ciclo e prejudicam a produção de fitomassa.

As modificações dos elementos meteorológicos, possíveis de ocorrer com a variação da época de semeadura, podem reduzir os rendimentos com diferentes culturas. Sabe-se que a quantidade de biomassa vegetal produzida está relacionada com a quantidade de radiação solar incidente e, também, com a sua eficiência de conversão em matéria seca. Quando não há outras condições limitantes, tais como deficiência hídrica e mineral, o rendimento é máximo. Neste caso, há uma relação linear entre matéria seca aérea e a radiação fotossinteticamente ativa (PAR). 
Na Figura 2 é possível observar esta relação linear de dependência, embora fraca, entre o rendimento em fitomassa com a mucuna preta e a PAR, cujo resultado coincide com os estudos de Barni et al. (1995b). A relação entre a produção de fitomassa da mucuna preta e a PAR, apresentou baixo coeficiente de determinação, explicando apenas $28 \%$ das variações no rendimento ao longo das oito épocas de semeadura, mas se observou que rendimentos acima de $0,800 \mathrm{~kg} \mathrm{~m}^{-2}$ só foram possíveis nas épocas em que a PAR atingiu valores acima de $8,53 \mathrm{MJ} \mathrm{m}^{-2} \mathrm{~d}^{-1}$, e isto ocorreu somente nas semeaduras de novembro, dezembro e janeiro (meses com menores deficiências hídricas). À medida que se atrasaram as semeaduras, a disponibilidade de radiação diminuiu, provocando redução no rendimento, como mostra a Figura 2, e este resultado indica que a eficiência de uso da radiação e, conseqüentemente, os maiores rendimentos, associam-se mais à disponibilidade hídrica que às reduções na interceptação da PAR. Confalone et al. (1999) também verificaram que a quantidade de radiação interceptada pela soja e sua eficiência de uso foram afetadas pelo estresse hídrico. A deficiência hídrica diminuiu o IAF, afetando a interceptação de radiação.

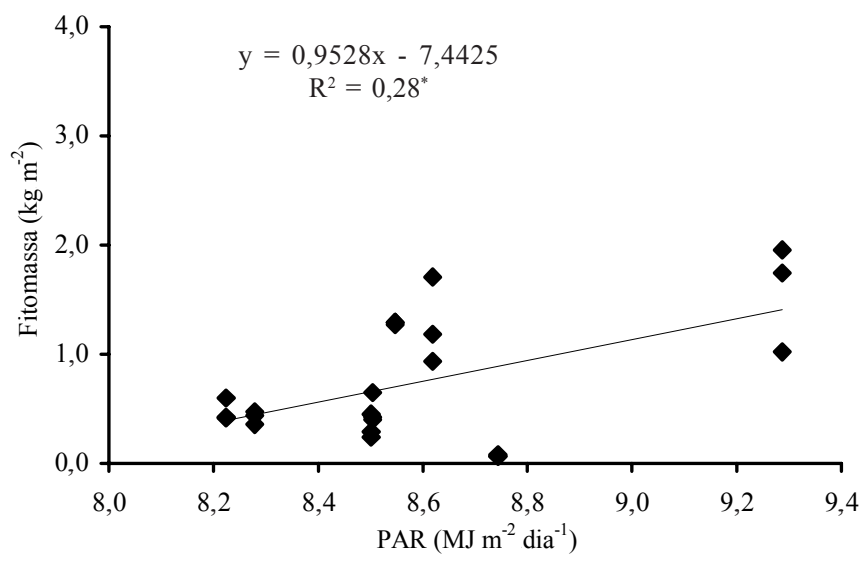

Figura 2. Relação entre a produção de fitomassa e radiação fotossinteticamente ativa (PAR), para a mucuna em oito épocas de semeadura

A Figura 3 confirma que o rendimento da mucuna foi mais afetado pela disponibilidade hídrica. A ETr/ETp, variável indicadora de deficiência hídrica, apresentou variabilidade entre 0,47 na época de maior deficiência hídrica, até 0,97 , na época de menor déficit hídrico. Conforme a Figura 3, com a diminuição dos valores da $\mathrm{ETr} / \mathrm{ETp}$, ocorreu redução no rendimento. No presente estudo esta relação, embora significativa, explicou apenas $45 \%$ das variações no rendimento da mucuna preta $\left(\mathrm{R}^{2}=0,45^{*}\right)$ e foi a variável que apresentou maior correlação com o rendimento da mucuna.

A medida em que se atrasou a semeadura, os valores da relação $\mathrm{ETr} / \mathrm{ETp}$ foram sendo reduzidos de valores próximos a 0,88 na quinta época de semeadura para 0,47 na oitava época. Comportamento semelhante foi verificado com os rendimentos em fitomassa seca, ou seja, as reduções em rendimento coincidiram com os períodos de maior deficiência hídrica, conforme mostra a Figura 3. Desta forma, pode-se atribuir, também, à deficiência hídrica, parte das reduções no rendimento

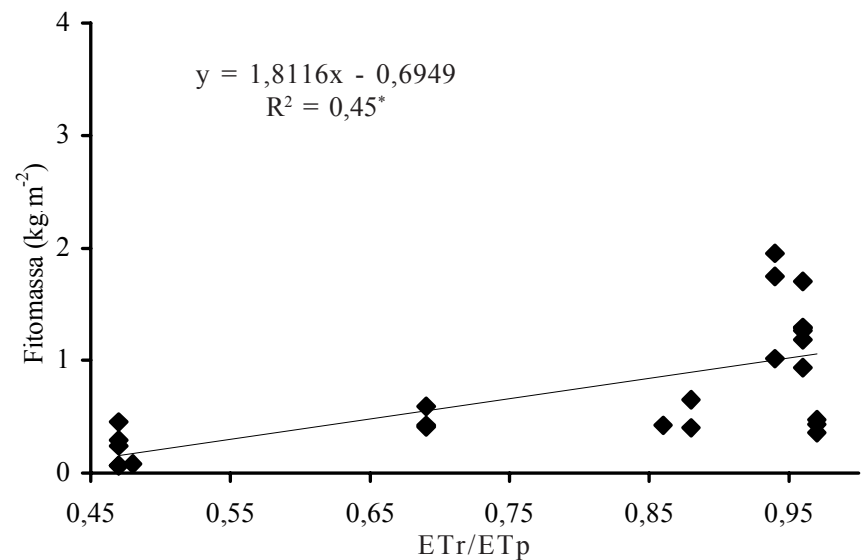

Figura 3. Relação entre a produção de fitomassa e o consumo relativo de água (ETr/ETp) para a mucuna preta

com a mucuna, uma vez que a deficiência hídrica também afeta a eficiência de uso da radiação e pode causar queda das folhas e acelerar a senescência das folhas mais velhas, como estratégia para reduzir o consumo de água (Begg \& Turner, 1976, citados por Thomas \& Costa, 1994).

Com a crotalária, o rendimento em fitomassa foi mais influenciado pelo fotoperíodo. A Figura 4 exibe a relação entre rendimento em fitomassa com a crotalária e o fotoperíodo. Com $\mathrm{R}^{2}=0,80^{*}$, esta foi a variável que melhor explicou as variações no rendimento dessa espécie. As produções superiores a 0,400 $\mathrm{kg} \mathrm{m}^{-2}$ ocorreram quando o período diurno foi acima de 13,8 h. Nas épocas em que o fotoperíodo foi inferior a este valor, os rendimentos decresceram até atingir valores abaixo de $0,100 \mathrm{~kg} \mathrm{~m}^{-2}$.

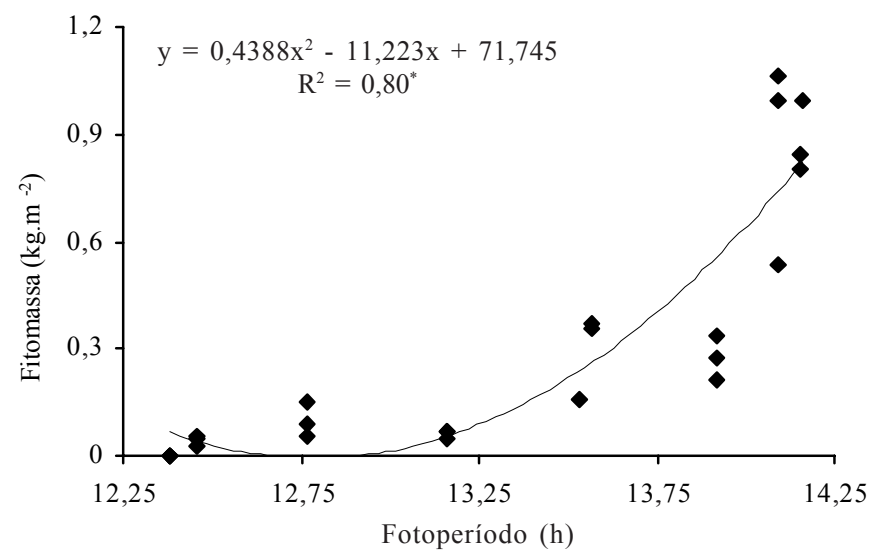

Figura 4. Relação entre a produção de fitomassa e o fotoperíodo, para a crotalária em oito épocas de semeadura

No caso da crotalária e à medida que os dias foram se tornando mais curtos, verificou-se redução no número de dias para a atingir o florescimento, comprovando a sensibilidade dessa espécie às variações no período de luz. A Figura 5 indica que o período entre a emergência e o florescimento variou entre 38 dias, na sétima época de semeadura, e 86 dias na primeira, cujo resultado confere com os resultados obtidos por Bulisani \& Roston (1993) e Campelo Júnior \& Santos (2001) que acrescentam que o fotoperíodo crítico da Crotalária juncea é de $13,6 \mathrm{~h}$. 


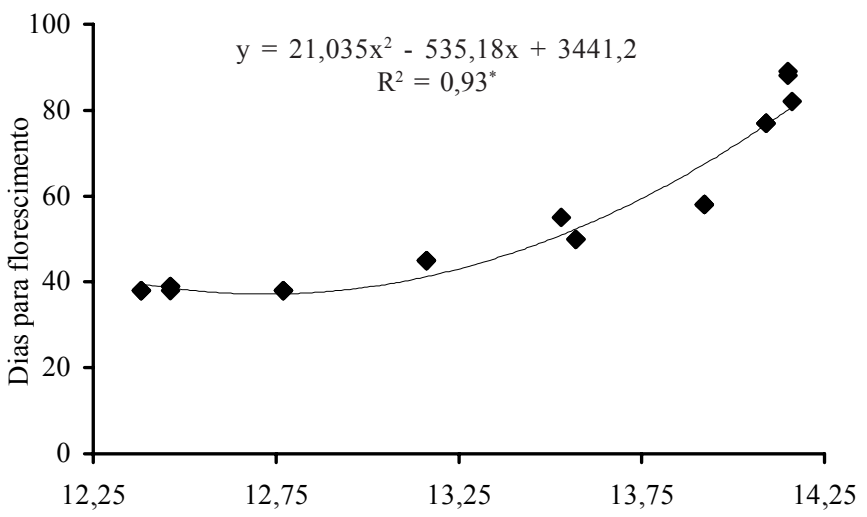

Fotoperíodo (horas)

Figura 5. Relação entre o número de dias necessários para o florescimento e o fotoperíodo para a crotalária, em oito épocas de semeadura

O modelo de regressão utilizado para explicar a variação no número de dias para a crotalária apresentar florescimento resultou em valor significativo de $\mathrm{R}^{2}=(0,93)$ indicando, assim, que essa relação é adequada para descrever tal processo. Por meio de análise de regressão Rodrigues et al. (2001) verificaram efeitos do fotoperíodo e da temperatura na duração do período entre a emergência e o florescimento, com diferentes variedades de soja. A reação fotoperiódica da crotalária é, normalmente, do tipo quantitativo, ou seja, o encurtamento dos dias favorece a indução ao florescimento.

$\mathrm{Na}$ oitava época de semeadura (jun.), a crotalária não apresentou emergência de plantas em quantidade suficiente para a determinação do rendimento e, na nona (jul.) época, não ocorreu emergência de plantas. Durante essas épocas, a precipitação acumulada foi de apenas $10,7 \mathrm{~mm}$, e houve redução no fotoperíodo e nos valores de temperatura. Neste último caso, a redução foi de 2,5 e $3,5^{\circ} \mathrm{C}$ em relação às épocas consideradas mais adequadas à semeadura.

O efeito provocado pelo estresse hídrico pode ser avaliado na Figura 6. A redução do consumo relativo de água (ETr/ETp) poderia ter provocado redução do rendimento em fitomassa com a crotalária, apenas na sétima e na oitava épocas de semeadura mas, tomando-se como base os rendimentos da primeira e segunda épocas, ocorreram reduções de rendimento nas terceira, quarta, quinta e sexta épocas, quando ETr/ETp foi maior que 0,90 , valor que indica suprimento adequado de água a uma cultura. $\mathrm{O}$ valor do coeficiente de determinação $\mathrm{R}^{2}=$ $0,20 *$ indica que apenas $20 \%$ das variações foram devidos à variação da ETr/ETp.

A baixa relação entre rendimento e ETr/ETp com a crotalária pode ser atribuída à sensibilidade dessa espécie ao fotoperíodo pois, mesmo nas épocas em que o suprimento de água não apresentou reduções relativamente significativas (ETr/ETp acima de 0,90), observou-se diminuição significativa em seu rendimento, Este resultado que diverge de Berlato et al. (1992) que apontam esta relação como eficiente indicadora da variação anual e espacial no rendimento da soja, que também apresenta sensibilidade fotoperiódica. Também diverge de Camargo et al. (1999) que observaram menor produtividade coincidente com menores valores da ETr/ETp.

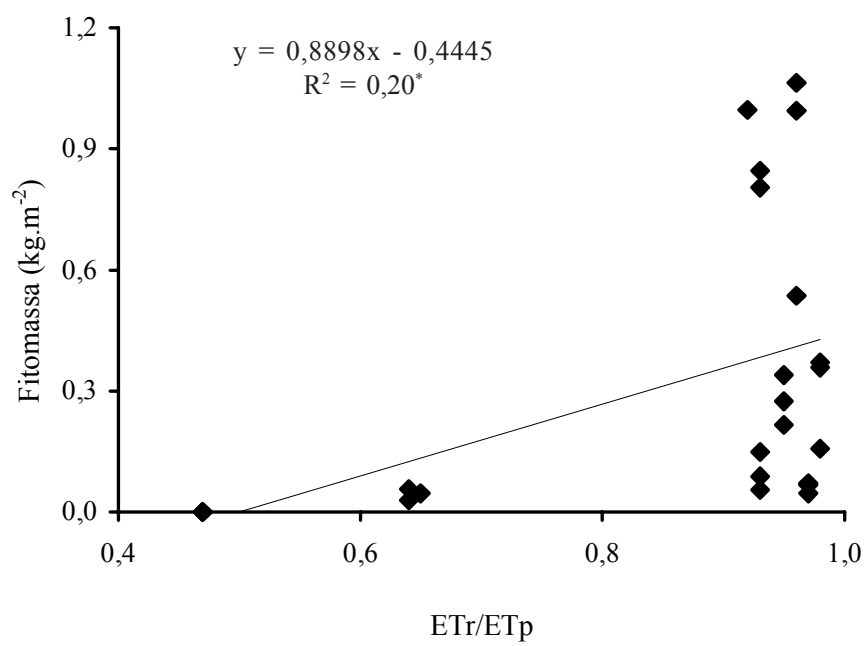

Figura 6. Relação entre o rendimento em fitomassa e o consumo relativo de água (ETr/ETp) para a crotalária juncea, em oito épocas de semeadura

Na Figura 7 é possível observar a relação entre a temperatura do ar, em graus-dia (GD) e o número de dias para a mucuna completar o subperíodo que se estende da emergência até o florescimento. Segundo Camargo et al. (1987), as plantas necessitam de certa quantidade de energia para completar o ciclo emergência-florescimento e há uma relação linear entre aumento de temperatura e desenvolvimento vegetal. Rodrigues et al. (2001) afirmam que o número de dias para o florescimento aumenta quando ocorrem temperaturas mais baixas.

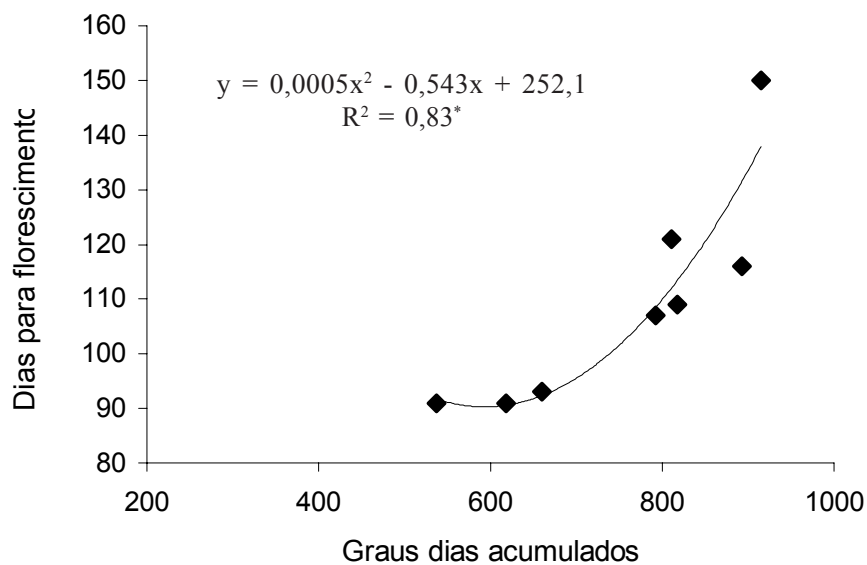

Figura 7. Graus-dia acumulados acima da temperatura base inferior $\left(15,7^{\circ} \mathrm{C}\right)$ desde a emergência até o florescimento da mucuna, em oito épocas de semeadura

A temperatura, representada por somas térmicas (GD), foi a variável meteorológica que melhor se correlacionou com a variação no número de dias para a mucuna apresentar florescimento $\left(\mathrm{R}^{2}=0,83^{*}\right)$. Esta correlação foi positiva e sugere que as variações no número de dias para a mucuna florescer são proporcionais às variações no acúmulo de GD, resultado que coincide com relatos de Medeiros et al. (2000) que descrevem ótimas correlações entre graus-dia com a duração do ciclo do feijoeiro, ou com seus estádios de desenvolvimento. 
Na Figura 7, os três menores valores correspondem às quarta, quinta e sexta épocas de semeaduras, ou seja, valores relativamente próximos entre si, de 91, 91 e 93 d para florescer e somas térmicas de 662, 620 e $546 \mathrm{GD}$, respectivamente. Os dois valores seguintes correspondem à terceira e à segunda épocas, com 107 e 109 dias, ou 791 e 817 GD. Na primeira época de semeadura, a mucuna necessitou de 116 dias para florescer e acumulou $893 \mathrm{GD}$, na oitava época de semeadura (junho), ela precisava de 121 dias para florescer e acumulou 808 GD, enquanto na sétima época de semeadura, a mucuna necessitou de 151 dias para florescer e acumulou $915 \mathrm{GD}$, mas acumulou, em média, nas oito épocas, 757 GD e necessitou, em média, de $109 \mathrm{~d}$ para o florescimento.

Este comportamento da mucuna preta apresenta divergências em relação à literatura, pois neste experimento a espécie apresentou diferenças no número de dias para atingir o florescimento, cuja variação pode ser explicada, em parte, pela diminuição nos valores médios da temperatura do ar durante a sétima e a oitava épocas de semeadura e pela atuação de outros fatores na acumulação de unidades térmicas durante o período emergência florescimento da mucuna preta. Segundo Queiroz et al. (1996) a ocorrência de temperaturas mais altas em períodos de veranico antecipa a ocorrência dos diversos estádios fenológicos da soja, provocando redução do ciclo emergênciafloração e, na altura das plantas, conseqüentemente diminuição na produção de fitomassa.

\section{CONCLUSÕES}

1. As maiores produções em fitomassa seca com a mucuna preta no local ocorreram nas semeaduras de novembro, dezembro e janeiro, e com a Crotalária juncea, nas semeaduras de novembro e dezembro.

2. Em condições favoráveis aos dois adubos verdes no local, a mucuna apresentou maiores rendimentos em fitomassa que a Crotalária juncea.

3. As insuficiências hídrica e térmica afetam a emergência das plantas e o rendimento com as duas espécies.

4. O rendimento em fitomassa e o número de dias para o florescimento com a crotalária são mais afetados pelo fotoperíodo.

5. A radiação fotossinteticamente ativa apresentou baixa correlação com os rendimentos da mucuna.

6. As somas térmicas (GD) apresentaram alta correlação com o número de dias para a mucuna florescer.

7. A ETr/ETp explica apenas $45 \%$ das variações no rendimento da mucuna e $20 \%$ no rendimento da crotalária e foi a variável que melhor se correlacionou com o rendimento da mucuna.

\section{LITERATURA CITADA}

Abboud, A.C. de S. Eficiência da adubação verde associada a fosfato natural de Patos de Minas. Itaquai: Universidade Federal Rural do Rio de Janeiro, 1986, 296p. Dissertação Mestrado
Alcantara, F.A. de; Furtini Neto, A.E.; Paula, M.B. de; Mesquita, H.A. de; Muniz, J.A. Adubação verde na recuperação da fertilidade de um Latossolo Vermelho-Escuro degradado. Pesquisa Agropecuária Brasileira, Brasília, v.35, n.2, p.277$288,2000$.

Amabile, R.F. Comportamento de adubos verdes em épocas de semeadura nos cerrados do Brasil Central. Piracicaba: Escola Superior de Agricultura Luiz de Queiroz, Universidade de São Paulo, 1996. 123p. Dissertação Mestrado

Arf, O.; Silva, L.S. da; Buzetti, S; Alves, M.C; Sá, M.E. de; Rodrigues, R.A.F; Hernandez, F.B.T. Efeito da rotação de culturas, adubação verde e nitrogenada sobre o rendimento do feijão. Pesquisa Agropecuária Brasileira, Brasília, v.34, n.11, p.2029-2036, 1999.

Barni, A.N.; Berlato, M.A.; Bergamaschi, H.; Riboldi, J. Rendimento máximo do girassol com base na radiação solar e temperatura: I. Absorção da radiação solar fotossinteticamente ativa. Pesquisa Agropecuária Gaúcha, Porto Alegre, v.1,n. 2, p. 185-199, 1995a.

Barni, A.N.; Berlato, M.A.; Bergamaschi, H.; Riboldi, J. Rendimento máximo do girassol com base na radiação solar e temperatura: II. Produção de fitomassa e rendimento de grãos. Pesquisa Agropecuária Gaúcha, Porto Alegre, v.1, n.2, p.201216, 1995b.

Berlato, M.A.; Fontana, D.C.; Gonçalves, H.M. Relação entre rendimento de grãos da soja e variáveis meteorológicas, Pesquisa Agropecuária Brasileira, Brasília, v.27, n.5, p.695702, 1992.

Brasil, Ministério das Minas e Energia, Secretaria Geral. Projeto RADAMBRASIL. Folha SD.21 Cuiabá; geologia, geomorfologia, pedologia, vegetação e uso potencial da terra, Rio de Janeiro, 1982.

Bulisani, E.A.; Roston, A.J. Leguminosas: adubação verde e rotação de culturas. In: Wutke, E.B.; Bulisani, E.A.; Mascarenhas, H.A.A. (coords.) Curso sobre adubação verde no Instituto Agronômico, 1., Campinas, 1993. Campinas, Instituto Agronômico, 1993. p.13-16. Documentos IAC, 35

Calegari, A. Leguminosas para adubação verde de verão no Paraná. Londrina: IAPAR, 1995. 117p.

Camargo, A.P. Florescimento e frutificação do café arábica nas diferentes regiões cafeeiras do Brasil. Pesquisa Agropecuária Brasileira, Brasília, v.20, n.7, p. 831-840, 1985.

Camargo, M.B.P. de; Brunini, O.; Miranda, M.A.C. de. Temperatura -Base para o cálculo dos graus-dia para cultivares de soja em São Paulo. Pesquisa Agropecuária Brasileira, Brasília, v.22, n.2, p.115-121, 1987.

Camargo, M.B.P. de; Ortolani, A.A.; Pedro Júnior, M.J.; Rosa, S.M. Modelo agrometeorológico de estimativa de produtividade para a cultivar de laranja valência, Bragantia, Campinas, v. $58, \mathrm{n} .1,1999$.

Campelo Júnior, J.H.; Santos, V.S. Limitações fotoperiódicas ao cultivo da crotalária em Mato Grosso. In: Congresso Brasileiro de Agrometeorologia, 12, 2001, Fortaleza. Anais... Fortaleza: SBAGRO, 2001. p.789-790.

Caruso, R. Cerrado brasileiro: desenvolvimento, preservação e sustentabilidade. Campinas: Fundação Cargill /CCD Editora, 1997. 112p. 
Confalone, A.E.; Dujmovich, M.N.; Canibano, A.; Sastre, P. Influência do déficit hídrico sobre a eficiência de utilização da radiação na produção de biomassa em soja. In: Congresso Brasileiro de Agrometeorologia, 11, 1999, Florianópolis. Anais... Florianópolis: SBAGRO, 1999. p.2561-2567.

Espindola, J.A.A.; Almeida, D.L. de; Guerra, J.G.M.; Silva, E.M.R. da; Souza, F.A. de. Influência da adubação verde na colonização micorrizica e na produção da batata-doce. Pesquisa Agropecuária Brasileira, Brasília, v.33, n.3, p.339-347, 1998.

Fageria, N.K; Souza, N.P. de. Respostas das culturas de arroz e feijão em sucessão à adubação em solo de cerrado. Pesquisa Agropecuária Brasileira, Brasília, v.30, n.3, p.359-368, 1995.

Fornasieri Filho, D.; Vieira, R.D.; Bellingier, P.A.; Fornasieri J.L. Comportamento de algumas leguminosas em distintas épocas de semeadura. Anais da Escola Superior de Agricultura “Luiz de Queiroz”, v.46, pt.1, p.257-274, 1989.

Malavolta, E.; Gomes, F.P.; Alcarde, J.C. Adubos e adubações. São Paulo: Nobel, 2000, 200p.

Medeiros, G.A. de; Arruda, F.B.; Sakai, E.; Fujiwara, M.; Boni, N.R. Crescimento vegetativo e coeficiente de cultura do feijoeiro relacionados a graus-dia acumulados, Pesquisa Agropecuária Brasileira, Brasília, v.35, n.9, p.1733-1742, 2000.

Nimer, E. Climatologia do Brasil. $2^{\text {a }}$.ed. Rio de Janeiro: IBGE, 1989, 422p.

Oliveira, O. J. de. Estresse hídrico e características agronômicas de materiais superprecoces de milho (Zea mays L.). Piracicaba: Escola Superior de Agricultura Luiz de Queiroz, Universidade de São Paulo, 2000. 89p. Tese Doutorado

Ometto, J.C. Bioclimatologia vegetal, São Paulo: Editora Agronômica Ceres, 1981.440p.

Pacheco, M.J.; Campelo Júnior, J.H. Necessidades hídricas da Crotalariajuncea L. Revista Brasileira de Agrometeorologia, Santa Maria, v.9, n.1, p.51-58, 2001.
Peixoto, C.P. Análise de crescimento e rendimento de três cultivares de soja em três épocas de semeadura e três densidades de plantas. Piracicaba: Escola Superior de Agricultura Luiz de Queiroz, Universidade de São Paulo, 1998. 151p. Dissertação Mestrado

Pinto, L.F.M.; Silva, S.C.; Sbrissia, A.F.; Carvalho, C.A.B.; Carnevalli, R.B.; Fagundes, J.L.; Pedreira, C.G.S. Dinâmica do acúmulo de matéria seca em pastagens de Tifton $85 \mathrm{sob}$ pastejo. Scientia Agricola, Piracicaba, v.58, n.3, p.439-447, 2001.

Queiroz, E.F. de; Molion, L.C.B; Gaudêncio, C.A.; Garcia, A. Um modelo matemático de previsão de ocorrência de estádios fenológicos de três cultivares de soja. Pesquisa Agropecuária Brasileira, Brasília, v.31, n.8, p.533-542, 1996.

Rodrigues, O.; Didonet, A.D.; Lhamby, J.C.B.; Bertagnolli, P.F.; Luz, J.S. Resposta quantitativa do florescimento da soja à temperatura e ao fotoperíodo, Pesquisa Agropecuária Brasileira, Brasília, v.36, n.3, p.431-437, 2001.

Rolim, G.S.; Sentelhas, P.C.; Barbieri, V. Planilhas no ambiente EXCEL para os cálculos de balanços hídricos: normal, seqüencial, de cultura e de produtividade real e potencial. Revista Brasileira de Agrometeorologia, Santa Maria, v.6, p.133-137, 1998.

Souza, L.D.N. de Adubação orgânica. Rio de Janeiro: Tecnoprint, 1989. 116p.

Thomas, A.L.; Costa, J.A. Influência do déficit hídrico sobre o rendimento da soja, Pesquisa Agropecuária Brasileira, Brasília, v.29, n.9, p.1.389-1.396, 1994.

Tubelis, A.; Nascimento, F.J.L. Meteorologia descritiva fundamentos e aplicações brasileiras, São Paulo: Nobel, 1992, $374 \mathrm{p}$.

Urchei, M.A.; Rodrigues, J.D.; Stone, L.F. Análise de crescimento de duas cultivares de feijoeiro sob irrigação, em plantio direto e preparo convencional. Pesquisa Agropecuária Brasileira, Brasília, v.35, n.3, p.497-506, 2000. 